\title{
Authors' response to letter to the editor by Zhiqiang Wu, Jiazhang Wu, and Zhibin Lan
}

\author{
Kristopher Clark ${ }^{1}$ Rebekah L. Goldstein ${ }^{2}$ Jaime E. Hart ${ }^{3} \cdot$ Merilee Teylan ${ }^{2}$ - Antonio A. Lazzari $\mathbb{1}^{1,4}$. \\ David R. Gagnon ${ }^{5}$ • Carlos G. Tun ${ }^{6}$ Eric Garshick ${ }^{3,7}$
}

Received: 9 March 2020 / Revised: 11 March 2020 / Accepted: 11 March 2020 / Published online: 24 March 2020

(c) International Spinal Cord Society 2020

\section{To the Editor:}

The letter by Zhiqiang $\mathrm{Wu}$, Jiazhang $\mathrm{Wu}$, and Zhibin Lan [1] lists several reasons for how low vitamin D levels may impact respiratory health, including providing additional mechanistic support for our findings, which suggest an association between low vitamin D levels and risk of chest illness in persons with chronic spinal cord injury. However, it should be noted that randomized controlled trials, as referenced in our report, have had mixed results on effects of vitamin D supplementation in preventing chest illnesses.

Guidelines currently exist for supplementing low vitamin D levels primarily to improve bone health [2]. Despite the mixed results of interventional studies, findings from observational studies such as ours suggest that individuals with the lowest vitamin D levels may be at increased risk of respiratory illness and could also benefit from supplementation. Further interventional studies are needed to determine whether vitamin D supplementation is beneficial in preventing respiratory illnesses and, if so, to determine which vitamin $\mathrm{D}$ levels should be targeted.

\section{Compliance with ethical standards}

Conflict of interest The authors declare that they have no conflict of interest.

Publisher's note Springer Nature remains neutral with regard to jurisdictional claims in published maps and institutional affiliations.

\section{Reference}

1. Wu Z, Wu J, \& Lan Z. Comment on: Plasma vitamin D, past chest illness, and risk of future chest illness in chronic spinal cord injury (SCI): a longitudinal observational study. Spinal Cord. (2020). https://doi.org/10.1038/s41393-020-0452-4. [Epub ahead of print].

2. Holick MF, Binkley NC, Bischoff-Ferrari HA, Gordon CM, Hanley DA, et al. Evaluation, treatment, and prevention of vitamin D deficiency: an Endocrine Society clinical practice guideline. J Clin Endocrinol Metab. 2011;96:1911-30. https://doi.org/10.1210/jc. 2011-0385.
Eric Garshick

eric.garshick@va.gov

1 Department of Medicine, Boston University/Boston Medical Center, Boston, MA, USA

2 Research and Development Service, VA Boston Healthcare System, West Roxbury, MA, USA

3 Channing Division of Network Medicine, Department of Medicine, Brigham and Women's Hospital and Harvard Medical School, Boston, MA, USA
4 Division of Primary Care and Rheumatology Section, VA Boston Healthcare System, West Roxbury, MA, USA

5 VA Cooperative Studies Program, VA Boston Healthcare System, Boston, MA, USA

6 Department of Physical Medicine and Rehabilitation, VA Boston Healthcare System, Boston, MA, USA

7 Pulmonary, Allergy, Sleep and Critical Care Medicine Section, VA Boston Healthcare System and Harvard Medical School, West Roxbury, MA, USA 